Document downloaded from:

http://hdl.handle.net/10251/148875

This paper must be cited as:

Payri, R.; Salvador, FJ.; Marti-Aldaravi, P.; Vaquerizo, D. (2017). ECN Spray G External Spray Visualization and Spray Collapse Description through Penetration and Morphology Analysis. Applied Thermal Engineering. 112:304-316. https://doi.org/10.1016/j.applthermaleng.2016.10.023

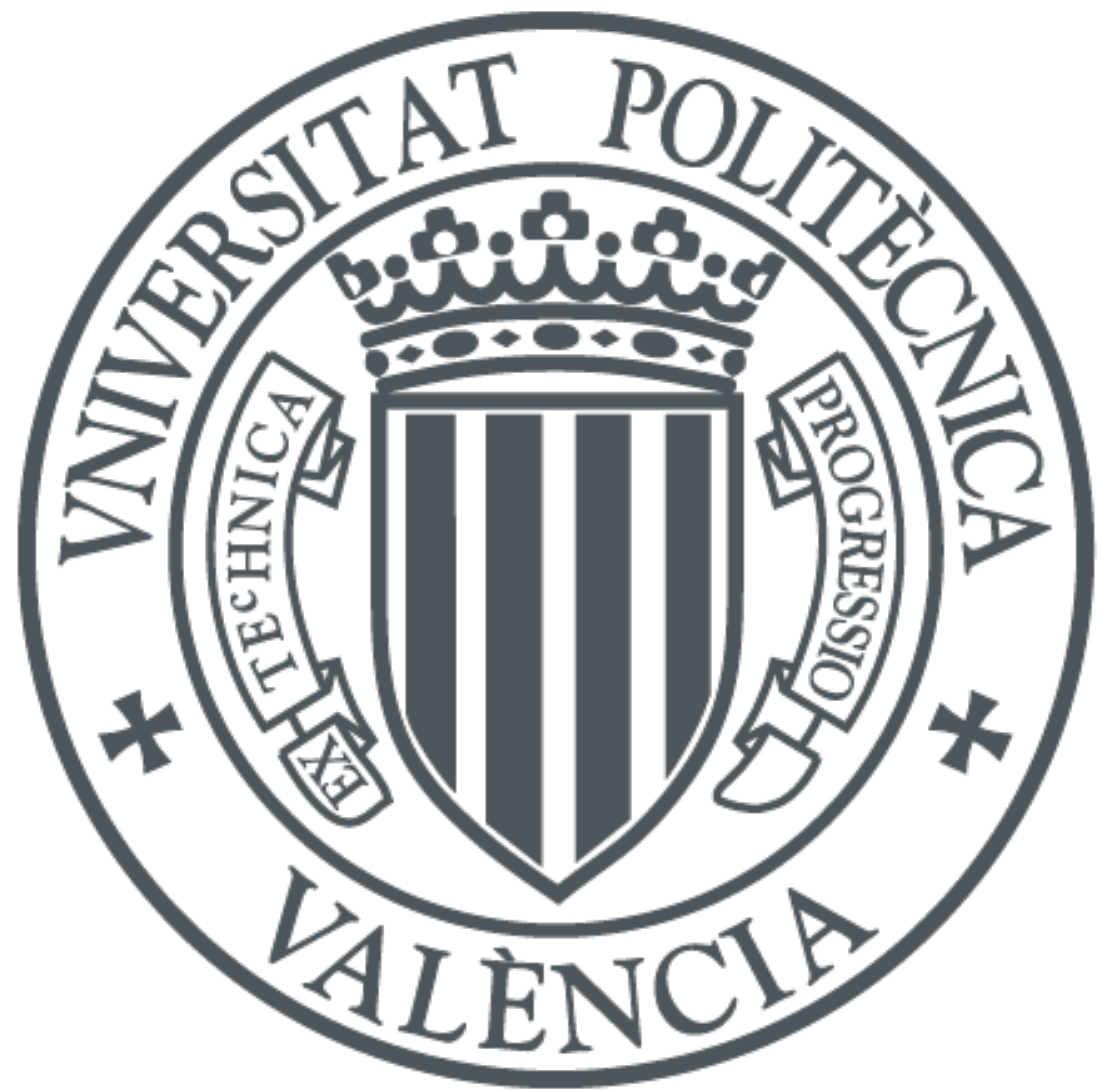

The final publication is available at

https://doi.org/10.1016/j.applthermaleng.2016.10.023

Copyright Elsevier

Additional Information 


\title{
ECN Spray G External Spray Visualization and Spray Collapse Description through Penetration and Morphology Analysis
}

\author{
R.Payri*, F.J. Salvador, P. Martí-Aldaraví, D.Vaquerizo \\ CMT-Motores Térmicos. Universitat Politècnica de València. Camino de Vera s/n, \\ E-46022 Valencia, Spain.
}

\begin{abstract}
Inside a DISI engine, a wide range of pressure and temperature conditions are possible, and with the current evolution of the systems, many of the conditions are subject to be encountered at the moment of injection. Given the great differences between Diesel injectors and GDi fuel injectors, the effects of such conditions on the development of the fuel injected can cause phenomena like flash boiling and spray collapse that fundamentally change the behavior of sprays. In this work, the Spray G injector developed by Delphi for the Engine Combustion Network (ECN) group has been tested in a High Pressure High Temperature Constant Pressure Flow Rig (HPHT - CPFR) in a wide range of experimental conditions capturing the liquid and vapor phases of the spray by means of DBI and Schlieren imaging. The work presents the results obtained by spray visualization through comparisons of parametric variations with special focus on the collapse of the spray that occurs under high ambient temperature and density conditions. Spray collapse has been described by showing the direct increase that can cause in spray penetration and the great closing effect that can produce to the aperture of the spray (spray angle). Several contour comparisons using the raw images and the detected contours have been discussed in order to support and further explain the observed trends.
\end{abstract}

Keywords: GDi, ECN, Spray G, Spray Collapse, Spray Penetration, Spray Angle, Schlieren, DBI, DISI, Gasoline Direct Injection 
Final author version, cite as:

R. Payri, F. J. Salvador, P. Martí-Aldaraví, \& D. Vaquerizo, ECN Spray G external spray visualization and spray collapse description through penetration and morphology analysis, Applied Thermal Engineering, vol. 112, pp. 304-316, 2017. doi:10.1016/j.applthermaleng.2016.10.023

\section{Nomenclature}

\begin{tabular}{rr}
\hline DISI & Direct injection spark ignition \\
GDi & Gasoline direct injection \\
ECN & Engine Combustion Network \\
HPHT & High pressure high temperature \\
CPFR & Constant pressure flow rig \\
DBI & Diffused back illumination \\
PFI & Port fuel injection \\
VCO & Valve covered orifice \\
CFD & Computational Fluid Dynamics \\
Re & Reynolds number \\
We & Weber number \\
LED & Light-emitting diode \\
ASOI & After start of injection \\
LL & Liquid Length \\
\hline
\end{tabular}

\section{Introduction}

GDi engines rely more on the quality and conditions of the delivered spray than the older PFI systems, where simpler injectors could suffice to provide with the needed fuel. Given the current trend toward the utilization of GDi engines, which have the potential for increasing power density, more economic fuel usage, cleaner operation, and incorporating advanced combustion strategies [1-3]; research is also shifting focus toward the newer systems [4-6]. GDi injectors can present phenomena such as flash boiling, cavitation and spray collapse that is more complex than the PFI counterparts and different than in the well documented behavior of Diesel sprays [7].

Given the interest put in the GDi systems, the Engine Combustion Network (ECN) group [8] started a new general topic focusing on six 8-orifice (stepped-hole) VCO injectors, purposely built by Delphi. The name of the primary reference condition is Spray G, which also extends to the denominations of the topics using these injectors [8]. The ECN Spray G topic provides

\footnotetext{
*Corresponding author rpayri@mot.upv.es
} 
Final author version, cite as:

R. Payri, F. J. Salvador, P. Martí-Aldaraví, \& D. Vaquerizo, ECN Spray G external spray visualization and spray collapse description through penetration and morphology analysis, Applied Thermal

Engineering, vol. 112, pp. 304-316, 2017. doi:10.1016/j.applthermaleng.2016.10.023

an opportunity to perform experimental work on a GDi injector applying the standards and knowledge acquired by the group from their work in their previous topics such as Spray A or Spray B. The Delphi Spray G injector has been characterized in terms of internal flow using rate of injection and rate of momentum [9]. Moulai et al. [10] also focused on the internal and near nozzle flow by performing rate of injection experiments, CFD simulations and near nozzle microscopy. Many of the differences in the internal flow behavior between GDi and Diesel injectors can be attributed to the difference in the internal geometry, for instance, the low needle lift (usually several times smaller than the orifices diameter) can create more instability and turbulence at nozzle outlet and increase the velocity of the spray [11]. Strek et al. [7] used X-ray radiography on a Spray G injector in order to characterize the internal geometry of the orifices and counter-bore with high resolution and were able to incorporate the data into a computational mesh for more accurate CFD calculations. Cheng et al. [12] performed experiments using nozzles with different characteristics and number of holes and showed the importance of the plume to plume interaction on the development of spray collapse under flashing conditions in a heated GDi injector. Flash boiling has also been studied in the Spray $G$ injectors by means of simulations $[7,13]$ and experiments [14-16]. Montanaro and Allocca [14] showed that for highly flashing conditions, a collapse of the sprays was taking place, transforming the shape of the spray from individual plumes to a cloud of finely atomized fuel. Zeng et al. [17] performed an intensive work of describing GDi multihole sprays by relating the macroscopic characteristics to the four forces of relevance: inertia, viscous, drag forces and surface tension by means of the Reynolds number (Re), Weber number (We) and air-to-fuel density ratio $\left(\rho_{a} / \rho_{f}\right)$. They found significant results and were able to create correlations using the dimensionless numbers and the extensive experimental data. However, The conditions selected for their study did not include flashing or spray collapsing conditions. Manin et al. [15], performed DBI, Schlieren and Mie scattering visualization experiments in the nominal Spray G conditions, and two additional conditions at higher density and temperature. In their work, they found the collapse of the spray that took place at the higher chamber density and temperature conditions and reported that causes for such phenomenon were probably a combination of enhanced evaporation at higher temperatures and wider sprays at higher ambient densities that created low pressure zones in the middle of the spray cone.

Given the fundamentally different behavior of the sprays under collapsing 
Final author version, cite as:

R. Payri, F. J. Salvador, P. Martí-Aldaraví, \& D. Vaquerizo, ECN Spray G external spray visualization and spray collapse description through penetration and morphology analysis, Applied Thermal

Engineering, vol. 112, pp. 304-316, 2017. doi:10.1016/j.applthermaleng.2016.10.023

conditions, and the importance that such change can have on evaporation and mixing (which directly affects combustion), the present work studies the liquid and vapor phases captured with DBI and Schlieren imaging techniques under extensive experimental conditions relevant for GDi injectors with focus on the spray collapsing phenomena. This phenomenon has been described by means of spray penetration and spray angle plots with the support of several raw images and detected contours. The relation among chamber density and temperature is discussed together with the dramatic changes in spray penetration, spray angle and morphology that the collapsing conditions created; and also the difficulty and need to characterize them. After introducing the problem, the paper shows the methodology used in the experimental and analytical work, detailing the configuration of the optical techniques and the main features of the processing of the images. Once the methodology and hardware are presented, the most representative results are shown, focusing on different parametric variations that allow to identify and isolate characteristics of the behavior of the spray and discuss them. Lastly, in the conclusions section, the work presented throughout the document is summarized.

\section{Experimental Apparatus.}

The hardware used for the current work was the Spray G injector serial \#26, a $20 \mathrm{MPa}$ maximum pressure multi-hole GDi injector, specifically manufactured by Delphi following the specifications accorded by the ECN group. The injector has been described in several papers focusing on rate of injection and rate of momentum characterization [9], on internal and near nozzle flow [10, 13], geometry and external spray development [15], where the nominal conditions and spray positioning details are also discussed. In the present work, only the primary orientation of the injector has been used (with electrical connector looking to the side). Iso-octane has been used as fuel, because it is the standard fuel selected by the ECN group for the Spray $\mathrm{G}$ topics. The explanations mentioning Diesel sprays are simply to compare to more familiar results to many readers, as the fuel sprays studies are very abundant in the Diesel field.

The experimental campaigns were done in a High Pressure and High Temperature test rig. The vessel consists in a Constant Pressure Flow Rig (CPFR) described in numerous works [18-20]. The temperature is monitored with two $0.5 \mathrm{~mm}$ thermocouples inside the vessel positioned close to the injector (but not so close that the fuel could impact on them). The temperature 
Final author version, cite as:

R. Payri, F. J. Salvador, P. Martí-Aldaraví, \& D. Vaquerizo, ECN Spray G external spray visualization and spray collapse description through penetration and morphology analysis, Applied Thermal

Engineering, vol. 112, pp. 304-316, 2017. doi:10.1016/j.applthermaleng.2016.10.023

is controlled by a PID that regulates the power output to two resistors inside the vessel. Measurements are only performed when the temperature reaches stabilization. In the optical configuration, two high speed cameras were used at the same time, one recording the images corresponding to Schlieren (or Shadowgraph), and another one recording the images coming from the DBI technique. The details of the optical configuration and the type of information extracted from each experiment is presented next.

\subsection{Optical set-up}

The optical techniques have been DBI and Single-Pass Schlieren Shadowgraph using two Photron SA5 high speed cameras. The field of view of both DBI and Schlieren are a lateral view of the injector nozzle. The complete set-up from a top view is presented in Fig 1. The image contains all of the optical equipment realistically represented and a horizontal cut of the High Pressure and High Temperature vessel in order to provide a direct view of the injector, the sprays and the windows.

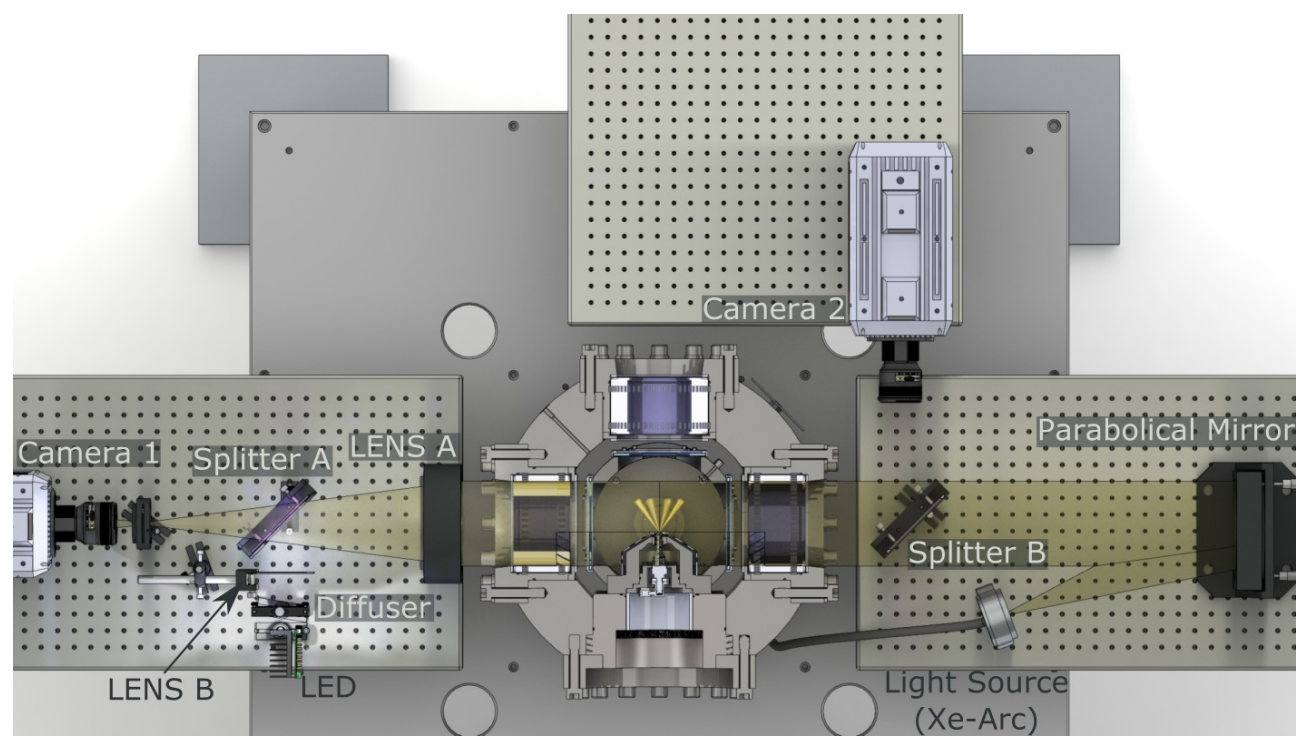

Figure 1: Schematic representation of the optical arrangement.

The frame rate and window size for the two cameras were not kept constant throughout the experiments in order to optimize the acquisition speed to the size needed for the different conditions. This practice allowed to record the high ambient density and temperature conditions, where the required 
Final author version, cite as:

R. Payri, F. J. Salvador, P. Martí-Aldaraví, \& D. Vaquerizo, ECN Spray G external spray visualization and spray collapse description through penetration and morphology analysis, Applied Thermal

Engineering, vol. 112, pp. 304-316, 2017. doi:10.1016/j.applthermaleng.2016.10.023

field of view is reduced, at a higher speed. Table 1 contains a summary of the different settings used in the experimental campaign. It is important to remark that the frame rate of the two cameras was always the same for a given condition in order to record the images for the two techniques at the same instants.

Table 1: Summary of settings for the two cameras.

\begin{tabular}{lllll}
\hline Technique & Camera & Frame Rate $[\mathrm{kfps}]$ & $\begin{array}{l}\text { Resolution } \\
{[\mathrm{pix} / \mathrm{mm}]}\end{array}$ & Illumination \\
\hline $\begin{array}{l}\text { Schlieren } \\
\text { DBI }\end{array}$ & Photron SA5 & $31-37.5$ & 5.78 & Xe-arc \\
\hline
\end{tabular}

The particular details for each subsystem are explained in the following subsections.

\subsubsection{Single-Pass Schlieren technique}

Single-Pass Schlieren is a widely used technique to characterize vapor penetration of single-hole injectors as it provides a lateral view of the vapor penetration [21]. Given the characteristics of a GDi injector, the included spray angle is very small $\left(\approx 80^{\circ}\right)$ compared to the Diesel case $\left(\approx 150^{\circ}\right)$, resulting in the spray moving forward (axially) more than sideways. For this reason, it makes sense to use the lateral view rather than the frontal view to characterize the morphology of the spray [14, 15, 22].

The optical path starts with the punctual light source at the bottom right of Fig 1, which was produced with a continuous Xe-Arc lamp connected to an optical fiber. The fiber was fitted to a holder with a $0.6 \mathrm{~mm}$ diameter hole. The light expands until it reaches the parabolic mirror, whose purpose is to collimate the light and redirect it to the test zone. The collimated (parallel) beams of light are subject to be deviated from their original path by density gradients in the path traveled. The beams of light that encounter fuel from the sprays, either in liquid or vapor phase, will be deviated from their original path. Downstream of the vessel, the light goes through a 400 $\mathrm{mm}$ focal length lens (Lens A) that will focus the light back to a point. In the position where the point is formed (focal length of Lens A), the shadowgraph cutting device is mounted. In this case, a circular pattern cutting device has been selected as it cuts the deviated light in a symmetrical manner. The cutting device or diaphragm is a critical part of the experiment because it 
Final author version, cite as:

R. Payri, F. J. Salvador, P. Martí-Aldaraví, \& D. Vaquerizo, ECN Spray G external spray visualization and spray collapse description through penetration and morphology analysis, Applied Thermal

Engineering, vol. 112, pp. 304-316, 2017. doi:10.1016/j.applthermaleng.2016.10.023

provides a direct control of the sensitivity of the technique. Right after the diaphragm, the high speed camera records the image formed in the set-up, which will be composed by black zones that represent the light that has been deviated by the spray and discarded in the cutt-off device, and clearer zones representing the background of the images where the light has not been deviated (or sufficiently deviated) and collected in the camera.

\subsection{2. $D B I$}

Diffused Back Illumination (DBI) has been used several times with satisfactory results [23, 24], and has also become the standard for Liquid Length measurements in the "Engine Combustion Network" [24]. The DBI technique was used to measure liquid penetration mainly because it was a priority to avoid reflections caused by the nozzle or windows.

The pulse of light (60 ns) is emitted by a purposely designed ultrafast white LED (bottom left of Fig 1). The light then passes through a plane diffuser and a lens (Lens B) to obtain a diffused light wide enough to cover the complete test area. The pulse then impacts a $50 \backslash 50$ (transparency $\backslash$ reflectivity) beam splitter (Splitter A), which redirects the light towards the injected fuel. When the pulses of light reach the spray, one out of three possibilities will take place: first, the light will encounter in its path sprayed fuel in liquid phase and therefore be blocked; two, the light will encounter the vapor phase of sprays and be slightly deviated and attenuated; and last, the light will go through a zone where only the ambient gas is present, in that case, it will be undisturbed. After the test zone and the window, the pulses of light are reflected by Splitter B to a high speed camera (camera 2), where the images formed in the experiment are recorded. Those images will be a composition of black zones (blocked light from liquid phase of the sprays), white zones (undisturbed light), and gray zones (zones with vapor phase). Given that in the case of DBI, the pulses of light going through the test area are not parallel (light is diffused), no focusing is done to the light, and no cut-off device is mounted in front of the camera; the gray and white areas do not possess sufficient contrast to be distinguished by the processing algorithms. The images captured with the camera are then basically images where the liquid phase of the spray appears dark and the background and vapor phase appear white or light gray. 
Final author version, cite as:

R. Payri, F. J. Salvador, P. Martí-Aldaraví, \& D. Vaquerizo, ECN Spray G external spray visualization and spray collapse description through penetration and morphology analysis, Applied Thermal

Engineering, vol. 112, pp. 304-316, 2017. doi:10.1016/j.applthermaleng.2016.10.023

\subsection{Test Matrix}

The experimental conditions selected ranged from $300 \mathrm{~K}$ to $800 \mathrm{~K}$ of chamber temperature and from $1 \mathrm{~kg} / \mathrm{m}^{3}$ to $9 \mathrm{~kg} / \mathrm{m}^{3}$ of gas density. Low density conditions for low temperature cases were not possible to measure given that the vessel requires a minimum air flow to operate. The test matrix was designed to provide with parametric variations of density, temperature and injection pressure. Table 2 shows the specific conditions measured in the experimental test campaign. Not all the possibilities of conditions were measured as that would lead to almost 300 measuring conditions. However, the number of measuring conditions was still quite high, resulting in more than 120 points.

Table 2: Summary of conditions tested in the experimental campaign.

\begin{tabular}{ll}
\hline Paremeter & Values \\
\hline Ambient Gas Density $\left[\mathrm{kg} / \mathrm{m}^{3}\right]$ & $1-2.1-3-3.5-4-5-6-7-8-9$ \\
Ambient Gas Temperature $[\mathrm{K}]$ & $300-333-400-500-600-700-800$ \\
Injection Pressure [MPa] & $10-20$ \\
Energizing Time $[\mu \mathrm{s}]$ & $680-1200$ \\
\hline
\end{tabular}

\section{Data processing methodology}

\subsection{Image Processing}

The processing of the images is one of the most important parts of any visualization data analysis [25]. The processing of all the images has been done using an internally developed algorithm in which the general processing of the images is independent of the type of technique used to capture them. Nonetheless, given the difference in the experiments and therefore in the images obtained, a preprocessing algorithm is used before the general processing algorithm to adapt the different kind of images. The strategy used in the preprocessing of the images is as follows:

1. Background subtraction. The preprocessing code prepares the background of the image and subtracts it to generate images where the minimum luminosity of the scene is normalized to zero. In the DBI technique, where the changes in density of the ambient is not reflected in the captured images, the background is considered static. For the 
Final author version, cite as:

R. Payri, F. J. Salvador, P. Martí-Aldaraví, \& D. Vaquerizo, ECN Spray G external spray visualization and spray collapse description through penetration and morphology analysis, Applied Thermal

Engineering, vol. 112, pp. 304-316, 2017. doi:10.1016/j.applthermaleng.2016.10.023

static case, a simple average of the first few images (before the injection event) is sufficient to prepare the background to extract (8 images were used). In the case of Schlieren, where the density gradients are made visible, the movement of the ambient gas in the background of the image is noticeable, which creates the necessity of calculating a new (dynamic) background for every image. In the dynamic case, the background is calculated in two steps: first, everything from the previous image that was not detected as spray is taken and put in the same place in the current image; and second, the part of the previous image where the sprays were detected is taken and filled with the corresponding positions of the background generated with the average of the first 8 images (the static background).

2. Threshold calculation. In order to detect the contour of the spray in the processing algorithm, it is necessary to create a binary (black and white) image, where the white part is the detected spray and the black part is the rest. A threshold has to be determined in order to create the binary image. The threshold is therefore a luminosity intensity value that represents the barrier of spray and background. There are many ways to calculate the threshold in order to perform binarization. Two methods have been used in this work depending on the type of technique. For DBI, an approach using an optical thickness threshold has been performed as it is the standard within the ECN group, the methodology used is discussed in [15], and consists on calculating the extinction of the images with respect of the background $\left(\log \mathrm{I} / \mathrm{I}_{0}\right)$ and considering the extinction bellow a certain value (0.6 in the current work) as liquid and the rest as background. For the Schlieren experiments, a fixed approach was selected $[18,26]$. In the fixed approach, the intensity threshold is calculated as a constant percentage (3.5\%) of the dynamic range of the image.

Once the preprocessing code finishes with the images, these are passed to the processing code for binarization and cleaning. The binarization is simply made by applying the threshold calculated in the previous step. Given that the original images are not perfectly homogeneous and some zones in the background can appear more illuminated, the resulting binary images and sectors do not perfectly represent the sprays and some cleaning is necessary. A binary image erosion is applied to the images in order to disconnect the white pixels areas that are connected by less than 2 pixels (connectivity). 
Final author version, cite as:

R. Payri, F. J. Salvador, P. Martí-Aldaraví, \& D. Vaquerizo, ECN Spray G external spray visualization and spray collapse description through penetration and morphology analysis, Applied Thermal Engineering, vol. 112, pp. 304-316, 2017. doi:10.1016/j.applthermaleng.2016.10.023

Once the erosion is performed, a minimum area filter is applied that eliminates any area that contains less than a set number of pixels, lastly, a binary image dilation is performed to restore the surface of the remaining white zones to their original size.

Fig 2 graphically shows the steps described previously. Top left presents the original image to be processed, top center shows the image with the background subtracted, top right is the result of the binarization with the calculated threshold. Once the binarization has been made, bottom left presents the image with the erosion filter applied whereas bottom center shows the image with the minimum area and dilation filters. Last, bottom right shows the original image with the detected contour overlapped.
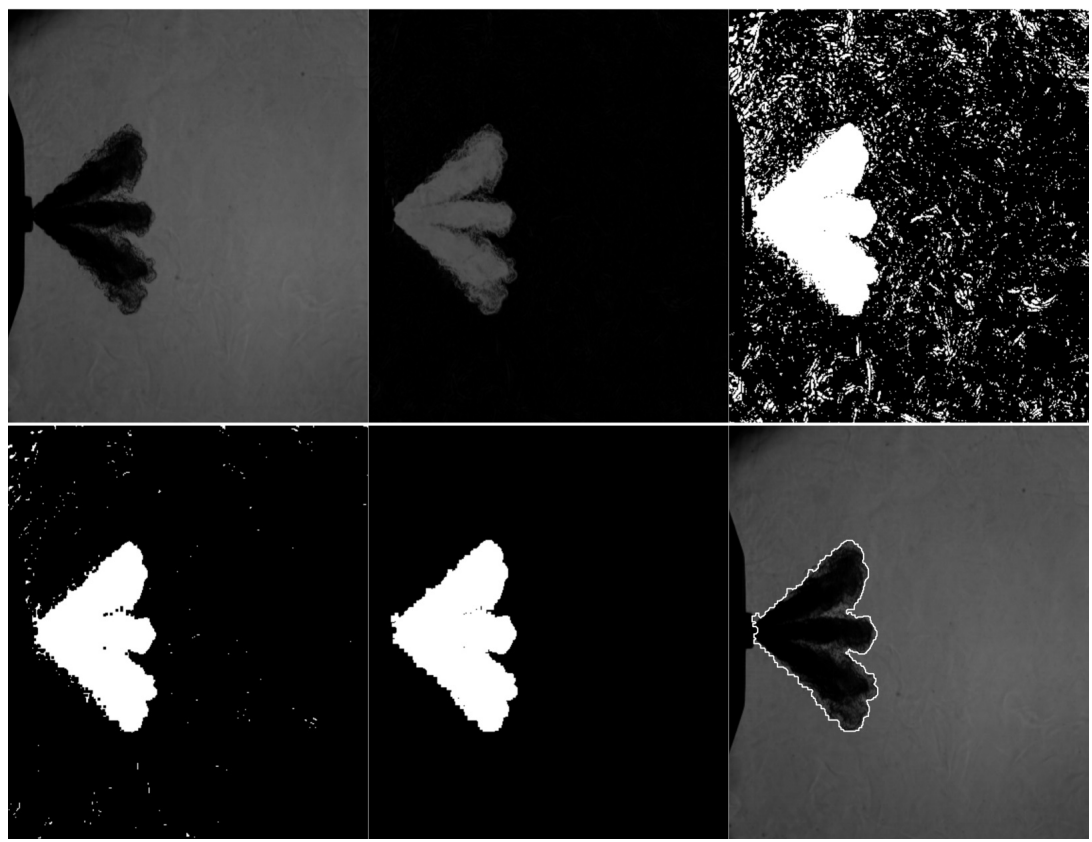

Figure 2: Example of the image processing for an Schlieren image. Top left, original image. Top center, original with subtracted background. Top right, raw binarization. Bottom left, erosion filter applied. Bottom center, minimum area and dilation filters applied. Bottom rigth, original image with detected contour overlapped.

\subsection{Contour Processing}

After the Image Processing algorithms detect the contour of the sprays, these contours pass to the post-processing codes to extract the results. The 
Final author version, cite as:

R. Payri, F. J. Salvador, P. Martí-Aldaraví, \& D. Vaquerizo, ECN Spray G external spray visualization and spray collapse description through penetration and morphology analysis, Applied Thermal

Engineering, vol. 112, pp. 304-316, 2017. doi:10.1016/j.applthermaleng.2016.10.023

two main results that can be generally extracted from the performed experiments are penetration and spray angle.

The penetration is extracted by selecting the furthest point of the spray contour, taking only the axial distance to the nozzle.

The angle is a difficult measurement to determine given the difficulty of extracting representative results due to the high dependence on the definition used. In the case of the liquid phase contour extracted with the DBI technique, the main source of uncertainty is that there are certain conditions where the shape of the spray is not completely conical (or triangular if it is observed from one side) and the lines composing the outer contour can be rounded. Fig 3 shows two different images from DBI experiments with the detected contour overlapped, the calculated angle plotted with dashed lines and the injection conditions given in the pictures. The angle has been calculated performing a least square fit with the lower and upper parts of contour. It can be noted the big difference between the shape of the contours from the two images. On the left-hand side image, where temperature and density are lower, the outer shape of the contour can be approximated with a triangle. However, on the right-hand side case, the outer part of the contour is more rounded and irregular. This creates the necessity to set the final limit of the contour used for the fit not very far away, whereas the initial limit has to be put very close to the nozzle (in order to avoid parallel lines if the first part of the spray is disregarded). The limits that were used after consideration were from $1 \%$ to $50 \%$ of the axial spray penetration.
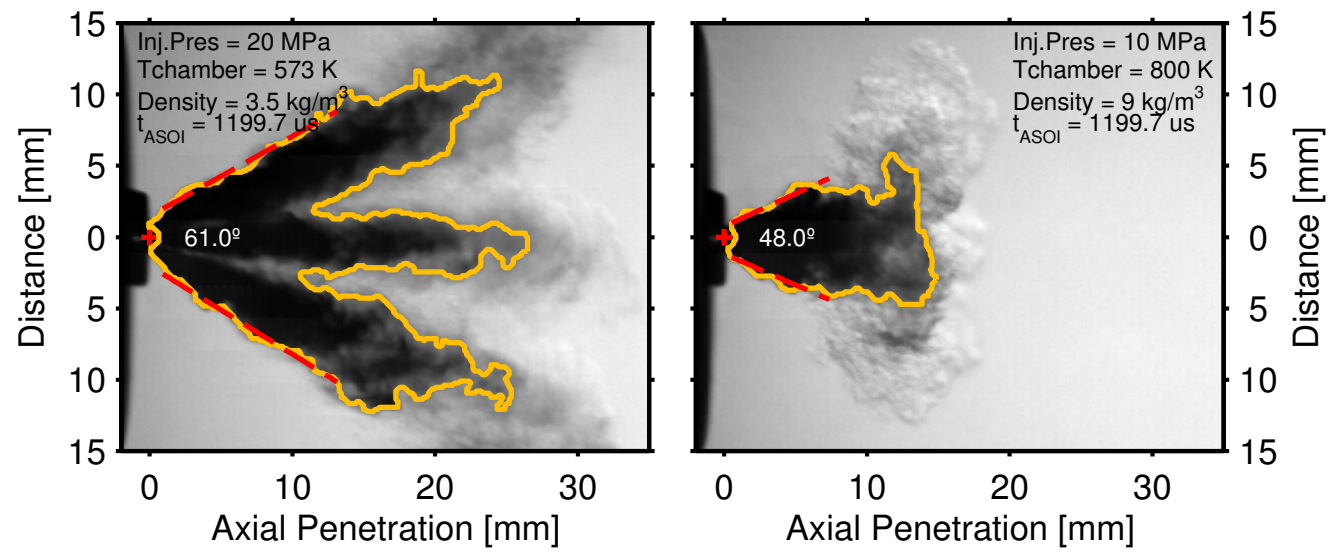

Figure 3: DBI Images at different temperature and density conditions with the detected contours overlapped to show the angle determination methodology. 
Final author version, cite as:

R. Payri, F. J. Salvador, P. Martí-Aldaraví, \& D. Vaquerizo, ECN Spray G external spray visualization and spray collapse description through penetration and morphology analysis, Applied Thermal

Engineering, vol. 112, pp. 304-316, 2017. doi:10.1016/j.applthermaleng.2016.10.023

Right-hand side image in Fig 3 shows the difficulty and uncertainty that may be encountered when calculating the angles using liquid phase captured via the DBI technique. For the vapor case, Fig 4 presents the same information extracted from Schlieren images. In this case, the low density condition at the left side of the figure shows how the same method applied in Fig 3 can also work for the Schlieren visualization. However, the right-hand side case with a higher value of density (but not as high as the right-hand side image of Fig 3) shows a different enough contour up to the point of not being able to apply an angle definition that can properly describe the phenomenon. This image, presents a thin spray cone in the beginning close to the nozzle but then rapidly expands to an oval shaped contour, effectively rendering the calculated angle meaningless. Given that the angle does not describe the first zone or second zone, the computed value does not describe the shape of the contour and therefore it does not hold any relation with the phenomena taking place. This phenomenon that occurs at moderate densities and can also occur at lower densities $\left(3.5 \mathrm{~kg} / \mathrm{m}^{3}\right)$ at later times After Start of Injection (ASOI), has made incompatible all of the definitions tried with the vapor phase of the spray and consequently caused that no vapor phase spray angles are shown in the current work. This is an example of how important more studies of GDi sprays are to properly and accurately describe the development of the fuel during and after the injection event.

\subsection{Data Averaging}

Ten repetitions have been obtained for each of the conditions. The repetitions are processed individually by the image processing algorithms and the results obtained by the contour processing are averaged using a moving average strategy. The procedure can be summarized as follows:

1. The data within the interval $t_{i} \pm \Delta t / 2$ is considered, where $t_{i}$ is the instantaneous time, and $\Delta t$ is the time window selected (9 $\mu$ s for all experiments).

2. Using the data selected in the interval, a linear fit is performed and the averaged value $\hat{y}$ is evaluated by computing $f\left(t_{i}\right)$, where $f(t)$ is the equation obtained for the fit.

3. The algorithm is repeated by moving $t_{i}$ with a certain step selected through the complete time of each dataset. 
Final author version, cite as:

R. Payri, F. J. Salvador, P. Martí-Aldaraví, \& D. Vaquerizo, ECN Spray G external spray visualization and spray collapse description through penetration and morphology analysis, Applied Thermal Engineering, vol. 112, pp. 304-316, 2017. doi:10.1016/j.applthermaleng.2016.10.023
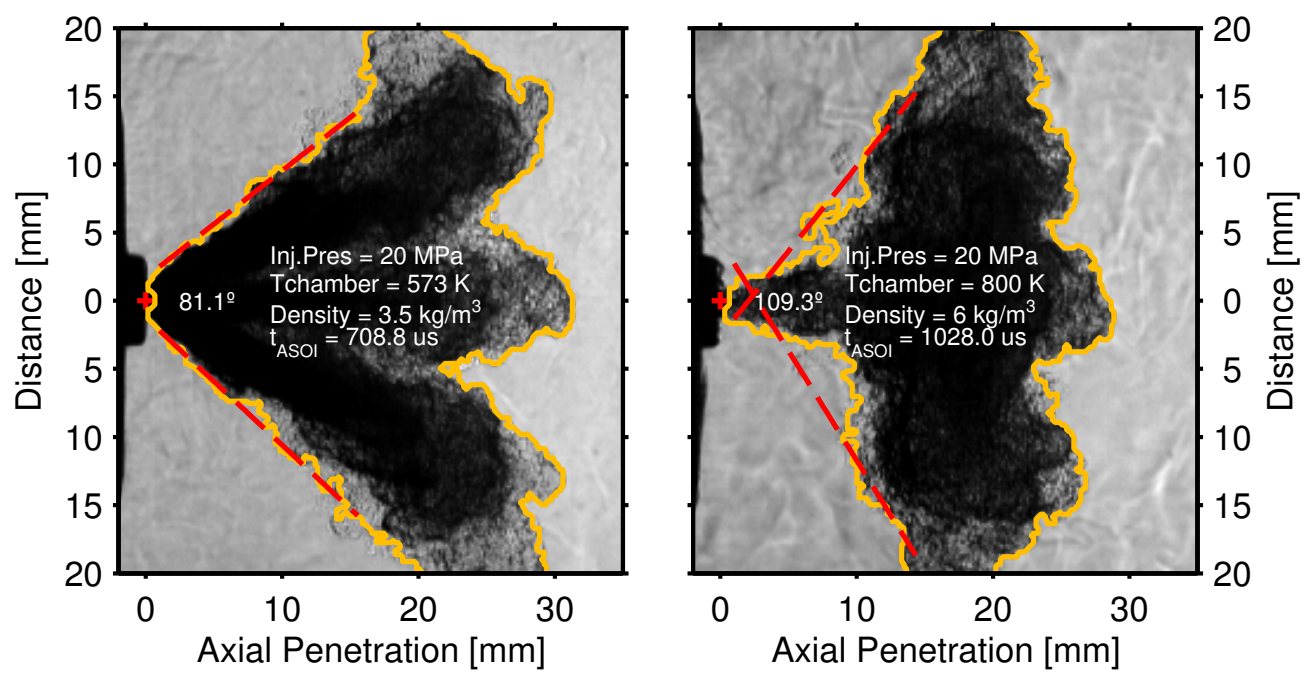

Figure 4: Schlieren Images at different temperature and density conditions with the detected contours overlapped to show the angle determination methodology for vapor phase.

\section{Results}

\subsection{Spray G conditions}

In order to compare the results obtained here at the standard conditions (for Spray G serial \#26) to those from other institution that obtained similar data in other Spray G injectors (serials \#16 and \#28), Fig 5 is presented. The figure shows the liquid phase (DBI) represented by dashed lines, the vapor phase (Schlieren) represented by continuous lines, and color shades representing the standard deviation of the averaged repetitions. The selection of line styles employed here has been maintained throughout the document. The plot compares the results obtained in this work with results extracted from [15], with the legend text showing the institution that provided the measurements and the serial of the injector tested. Even though the injectors are not the same, much effort was done by the ECN group to get very similar hardware that could provide comparable results. It can be seen that the results from the three injectors show good agreement between the institutions (General Motors and CMT-Motores Térmicos). 
Final author version, cite as:

R. Payri, F. J. Salvador, P. Martí-Aldaraví, \& D. Vaquerizo, ECN Spray G external spray visualization and spray collapse description through penetration and morphology analysis, Applied Thermal

Engineering, vol. 112, pp. 304-316, 2017. doi:10.1016/j.applthermaleng.2016.10.023

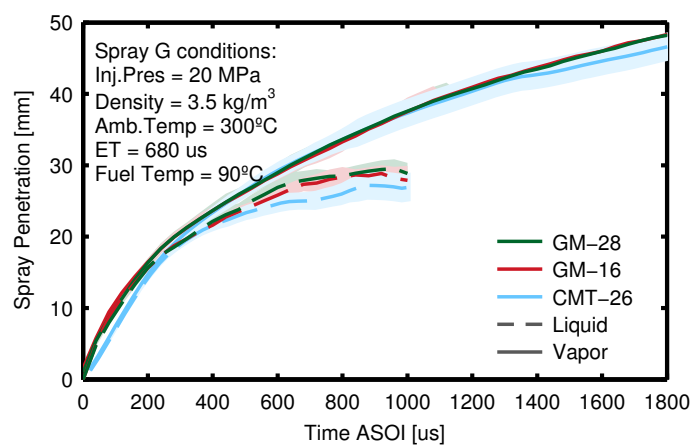

Figure 5: Comparison of liquid and vapor penetration measured with DBI and Schlieren experiments respectively. Figure compares data from General Motors extracted from [15] and data obtained in the current work.

\subsection{Effects of gas density variations}

Many different density conditions may be encountered inside a gasoline engine, and the GDi injector has to be able to supply the proper quantity of fuel at all of these possible conditions. A typical Diesel injector has a very clear relation between vapor and liquid penetration with density, and in fact, density is one of the most influential factors on vapor penetration $[18,27,28]$.

Fig 6 shows vapor and liquid penetration results for different densities at $500 \mathrm{~K}$ (top) and $700 \mathrm{~K}$ (bottom). The density in the top figure ranges from approximately the same values as for the bottom one. It can be appreciated that the trends of liquid and vapor penetration on the top figure are the ones expected and many times reported from Diesel spray research. In the density variation at $700 \mathrm{~K}$, the temperature is sufficient to make possible the stabilization of liquid penetration within the captured time window. Said stabilization can be seen from around $200 \mu$ s ASOI in the lower density conditions. However, the liquid penetration for the higher density conditions (more than $4 \mathrm{~kg} / \mathrm{m}^{3}$ ) does not stabilize, but rather it keeps increasing and even surpassing the liquid penetration of the lower density conditions. The phenomena taking place here is quite different to what has been previously reported in Diesel research and it is related to the collapse of the spray plumes, which can also be encountered when experimenting GDi sprays in flash boiling conditions [29, 30]. Manin et al. [15] performed experiments using different units of the same hardware used in the current work for the Spray G standard condition and two other conditions at higher density and temperature. It was reported that for the cases with high density and tem- 
Final author version, cite as:

R. Payri, F. J. Salvador, P. Martí-Aldaraví, \& D. Vaquerizo, ECN Spray G external spray visualization and spray collapse description through penetration and morphology analysis, Applied Thermal

Engineering, vol. 112, pp. 304-316, 2017. doi:10.1016/j.applthermaleng.2016.10.023
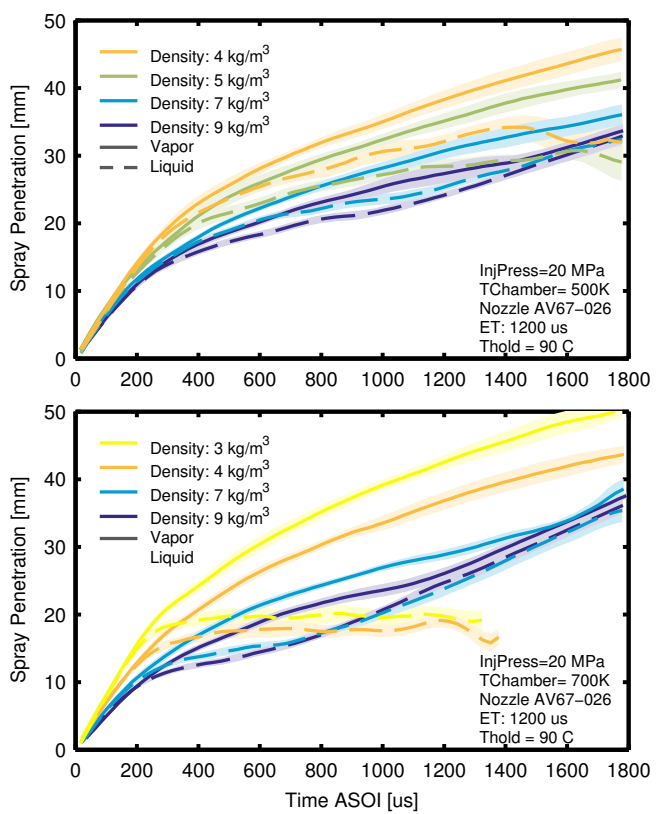

Figure 6: Density variations for $500 \mathrm{~K}$ (top) and $700 \mathrm{~K}$ (bottom) for $20 \mathrm{Mpa}$ injection pressure and $1200 \mu \mathrm{s}$ of energizing time for vapor and liquid penetration.

perature, the collapse of the spray plumes inwards (towards the injector axis) became more important. It was also reported, as it was in [31], that the spray collapse was probably taking place due to a combination of factors. It was hypothesized that the enhanced evaporation caused by increased density and temperature, which would increase the air entrainment and therefore lead to wider individual spray plumes; promotes lower pressure inside the spray cone thus increasing the possibility of spray collapse. As it has been stated before, a combination of density and temperature conditions promote the development of spray collapse, which can increase penetration [15, 29-31]. The change in penetration and the dramatic change in the spray morphology suggest an important change in the mixing dynamics that could also develop inside an engine cylinder. Even though the test matrix performed in [15] did not allow to make parametric variations of density and temperature, spray collapse phenomenon was linked to a combination of density, temperature and injection conditions. The large test matrix conducted in the work presented here makes possible to perform such parametric variations that can help with the characterization of the complex phenomena taking place in 
Final author version, cite as:

R. Payri, F. J. Salvador, P. Martí-Aldaraví, \& D. Vaquerizo, ECN Spray G external spray visualization and spray collapse description through penetration and morphology analysis, Applied Thermal

Engineering, vol. 112, pp. 304-316, 2017. doi:10.1016/j.applthermaleng.2016.10.023

gasoline sprays injection.

Fig 7 shows the detected contours (liquid phase) for two of the conditions whose results were shown in Fig 6 (bottom). The conditions selected are the most different ones in terms of density in order to evaluate its effect more clearly. It can be seen in the figure that the first (top) images behave as expected, with the lower density case providing a higher penetration and thiner sprays. However, from the second to the third pictures, the spray starts to collapse inwards in the high density case and no individual plumes can be identified. For a given instant after the Start of Injection (SOI), the liquid penetration of the lower density case stabilizes, reaching the so-called Liquid Length value. The collapsing of the sprays in the high density case produces several effects that contribute to increase the axial penetration and change the evaporation rate of the spray:

1. The momentum of the sprays is now only directed axially, away from the nozzle, which can effectively increase the axial distance between the fuel and the nozzle tip.

2. The spray cone angle is greatly diminished and no individual sprays can be identified, reducing the area in contact with surrounding hot air, and consequently diminishing the rate of evaporation.

3. The collapsing of the sprays towards the injector axis and the diminished evaporation rate can create a zone with high fuel concentration. This zone can shield the fuel still being injected from getting in contact with hot air. This effect would significantly reduce momentum exchange between the sprays and the ambient gas and further prevent evaporation.

These effects explain the previously observed behavior in Fig 6 (bottom). The liquid penetration, which is greatly affected by the evaporation rate, starts normally at the beginning of the injection, until the spray collapse phenomenon develops. Then, the relation between spray penetration and density inverts and the conditions at higher densities start penetrating more as the phenomena gets more severe.

As it has been stated before, spray collapse is a combination of several factors. This can be appreciated when comparing top and bottom graphs in Fig 6. Even though the maximum densities are the same, spray collapse is taking place less intensively and later in the low temperature case $(500 \mathrm{~K})$ than in the high temperature case $(700 \mathrm{~K})$. It can be noted that no inversion 
Final author version, cite as:

R. Payri, F. J. Salvador, P. Martí-Aldaraví, \& D. Vaquerizo, ECN Spray G external spray visualization and spray collapse description through penetration and morphology analysis, Applied Thermal

Engineering, vol. 112, pp. 304-316, 2017. doi:10.1016/j.applthermaleng.2016.10.023

399 of penetration is taking place in the low temperature case until after the end of the injection $(\approx 1500 \mu \mathrm{s} \mathrm{ASOI})$. 
Final author version, cite as:

R. Payri, F. J. Salvador, P. Martí-Aldaraví, \& D. Vaquerizo, ECN Spray G external spray visualization and spray collapse description through penetration and morphology analysis, Applied Thermal Engineering, vol. 112, pp. 304-316, 2017. doi:10.1016/j.applthermaleng.2016.10.023

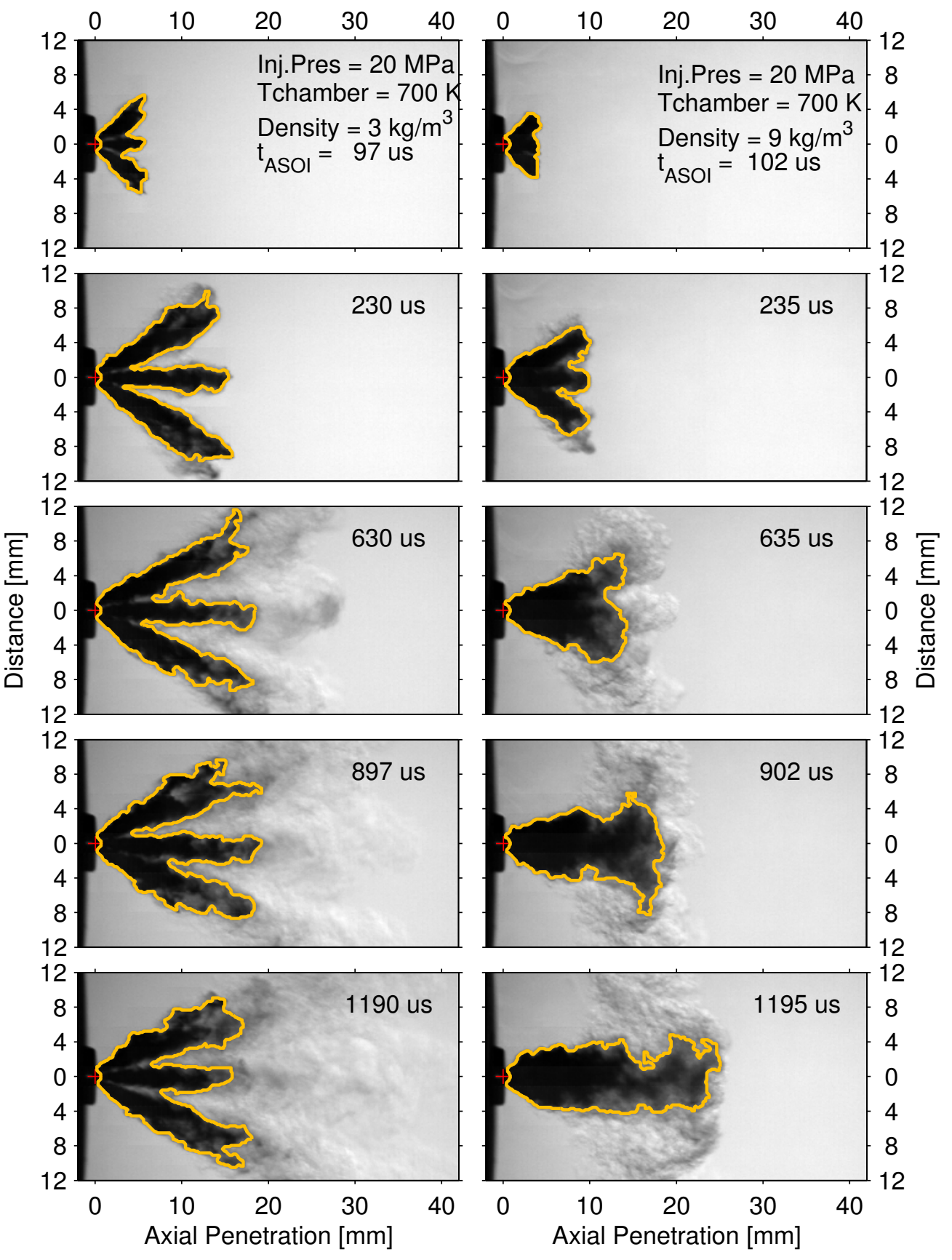

Figure 7: Liquid spray comparison between lower density conditions (left) and higher density conditions (right) using raw images and the detected contours. 
Final author version, cite as:

R. Payri, F. J. Salvador, P. Martí-Aldaraví, \& D. Vaquerizo, ECN Spray G external spray visualization and spray collapse description through penetration and morphology analysis, Applied Thermal

Engineering, vol. 112, pp. 304-316, 2017. doi:10.1016/j.applthermaleng.2016.10.023

Given the differences seen in Fig 7 in the spray morphology between the high and low density cases, another useful parameter to analyze the behavior of the sprays is the spray angle. Fig 8 shows the angle of the spray calculated according to section 3.2. As it was stated, only the liquid phase angle is presented due to the big uncertainties in the vapor angle determination.
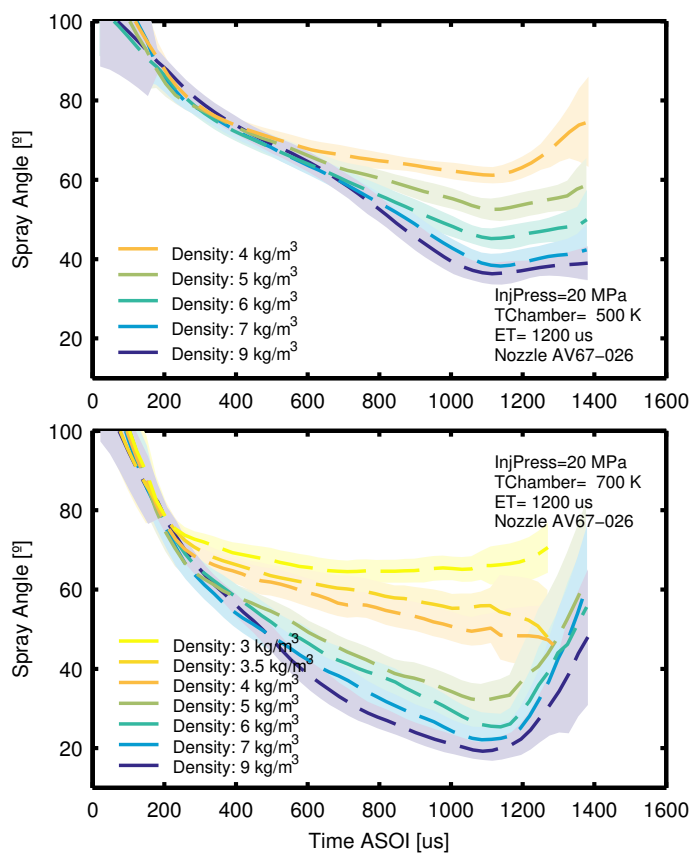

Figure 8: Liquid spray angle for different density values for $500 \mathrm{~K}$ (top) and $700 \mathrm{~K}$ (bottom) for $20 \mathrm{MPa}$ injection pressure and $1200 \mu$ s of energizing time.

Fig 8 presents a low temperature case in the top part $(500 \mathrm{~K})$ and a high temperature case in the bottom part $(700 \mathrm{~K})$. The conditions presented here are the same than those presented in Fig 6 . It can be observed that even in the low temperature case, a higher value of density is accompanied by a smaller spray angle, which suggests that there is still spray collapse happening at $500 \mathrm{~K}$ (although in a small degree). The lower level of spray collapse happening at $500 \mathrm{~K}$ (top graph), compared to the one observed in the $700 \mathrm{~K}$ case (bottom graph), is not sufficient to create a big enough effect in spray penetration to be noted when analyzing top graph of Fig 6 . In order to corroborate that there is still spray collapse happening at $500 \mathrm{~K}$ but in a smaller degree than at $700 \mathrm{~K}$, Fig 9 is presented. Fig 9 provides similar 
Final author version, cite as:

R. Payri, F. J. Salvador, P. Martí-Aldaraví, \& D. Vaquerizo, ECN Spray G external spray visualization and spray collapse description through penetration and morphology analysis, Applied Thermal

Engineering, vol. 112, pp. 304-316, 2017. doi:10.1016/j.applthermaleng.2016.10.023

comparison than Fig 8 at a lower temperature. It can be appreciated how in this example, the relation between spray angle and density follows the expected trend (opposite to the one appearing in Fig 8), where an increase in density produces an increase in the angle of the spray [27, 32].

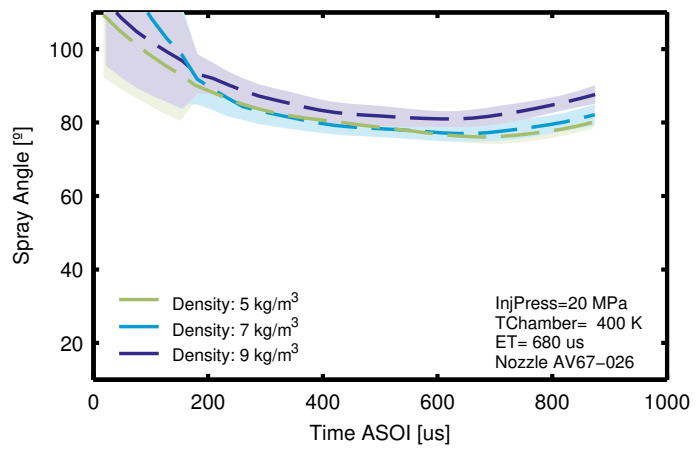

Figure 9: Density variations at non-vaporizing conditions (400 K) for liquid spray angle.

\subsection{Effect of gas temperature variations}

As shown in the test matrix (section 2.2), the temperature was varied from $300 \mathrm{~K}$ to $800 \mathrm{~K}$ for the measurements (not all the temperatures were measured for all the densities). Fig 10 shows the effects of changing the gas temperature at $4 \mathrm{~kg} / \mathrm{m}^{3}$ (top) and $9 \mathrm{~kg} / \mathrm{m}^{3}$ (bottom). On the low density case, the graph shows what could be a typical behavior with temperature, the liquid phase is greatly affected by the variation in temperature, ranging from no evaporation, and therefore almost no difference with the vapor penetration at $330 \mathrm{~K}$, to highly evaporating condition, and therefore a big difference with vapor penetration at $800 \mathrm{~K}$.

The vapor penetration in Diesel sprays is almost independent of the temperature at iso-density, in evaporating conditions [18]. In this case, it can be seen that once the temperature goes beyond $573 \mathrm{~K}$, the differences in vapor penetration are not very high but there is still a small inverse relation with temperature. The differences can be attributed to small changes in the morphology of the sprays at different temperatures, given the close relation between spray penetration, evaporation, and plume to plume interaction showed in the previous section.

The bottom graph in Fig 10 shows a different phenomenon than in the low density case. Here, the development of sprays is similar to what was shown in Fig 6 for the high temperature case, with the difference that now the inversion 
Final author version, cite as:

R. Payri, F. J. Salvador, P. Martí-Aldaraví, \& D. Vaquerizo, ECN Spray G external spray visualization and spray collapse description through penetration and morphology analysis, Applied Thermal

Engineering, vol. 112, pp. 304-316, 2017. doi:10.1016/j.applthermaleng.2016.10.023
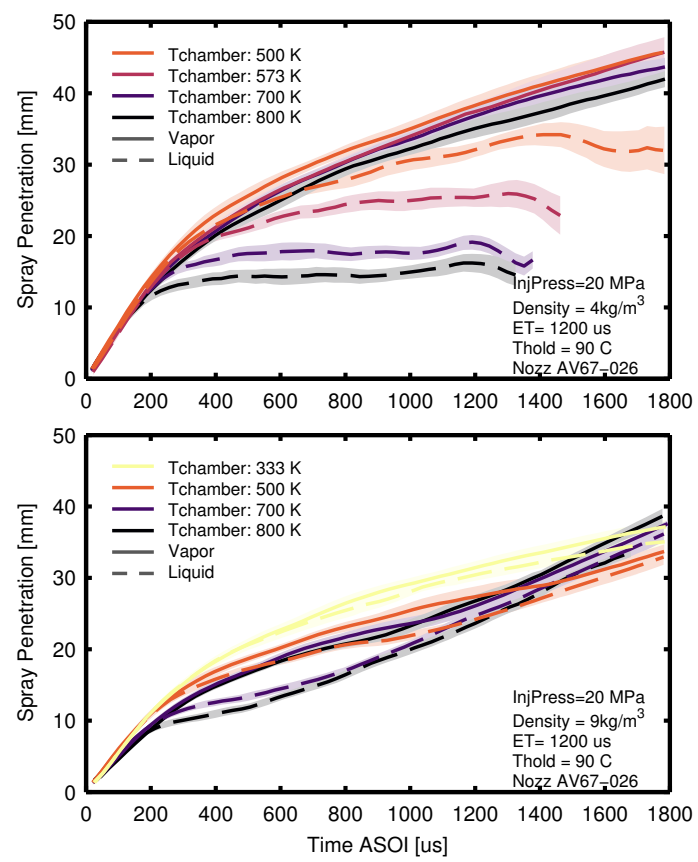

Figure 10: Temperature variations for $3 \mathrm{~kg} / \mathrm{m}^{3}$ density (top) and $9 \mathrm{~kg} / \mathrm{m}^{3}$ (bottom) and $200 \mathrm{MPa}$ injection pressure for liquid and vapor penetration.

of spray penetration has also extended to the vapor phase. The density of the gas is much more important than its temperature for vapor penetration, which is why the comparison presented here can show a clearer picture of the effect of collapse on the penetration of the vapor. This is because, in this case, increments in temperature have little effect in vapor penetration (in fully evaporation conditions) while greatly affecting spray collapse (as it has been shown in the previous section). On the other hand, in Fig 6 (bottom) the different densities comparison at iso-temperature showed the effects of density in spray collapse together with the effects in vapor penetration, which prevented the apparition of inversion in trends of vapor penetration.

Fig 11 shows the Schlieren contours for the lowest and highest density conditions in Fig 10 (bottom). Given that the conditions represented at the left-hand side of the comparison are non evaporative, the full spray is in liquid phase. As it was shown in [32], a liquid spray phase has a higher penetration rate than a vaporizing one at the same density. This is related to the ability of the vapor phase of the spray to exchange momentum with the 
Final author version, cite as:

R. Payri, F. J. Salvador, P. Martí-Aldaraví, \& D. Vaquerizo, ECN Spray G external spray visualization and spray collapse description through penetration and morphology analysis, Applied Thermal

Engineering, vol. 112, pp. 304-316, 2017. doi:10.1016/j.applthermaleng.2016.10.023

ambient gas at a higher rate than if the sprays were liquid. It can be seen in Fig 11 that for the first time steps, the expected behavior takes place, and the liquid penetrates more than the vapor. It can be noted in the right-hand side that even in those first time steps, spray collapse is developing and the individual plumes are not identifiable. The spray for the high temperature case penetrates slowly at the beginning of the injection until mass concentrates and shields the incoming spray from the hot surrounding air. This can produce a significant decrease in aerodynamic drag and a decrease in evaporation rate which results in more liquid fuel in the spray tip. These two effects created by the high fuel concentration zone that put collapsing liquid fuel in the spray tip, can explain the increase in spray penetration and therefore explain the inversion in the trends taking place in Fig 10. 
Final author version, cite as:

R. Payri, F. J. Salvador, P. Martí-Aldaraví, \& D. Vaquerizo, ECN Spray G external spray visualization and spray collapse description through penetration and morphology analysis, Applied Thermal Engineering, vol. 112, pp. 304-316, 2017. doi:10.1016/j.applthermaleng.2016.10.023

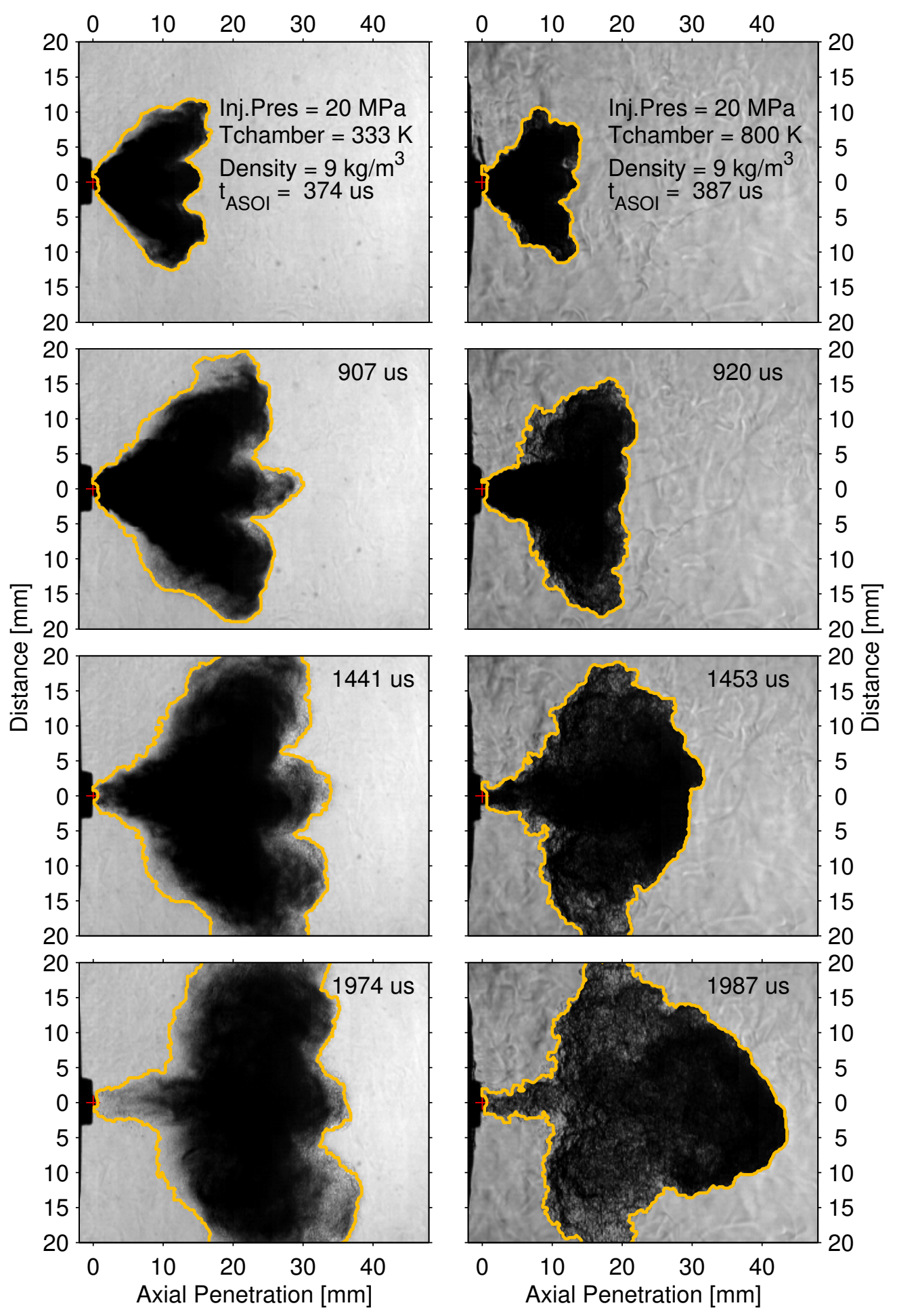

Figure 11: Vapor spray comparisons betweeß low temperature case (left) and high temperature case (right) at $9 \mathrm{~kg} / \mathrm{m}^{3}$ of chamber density using raw images and the detected contours overlapped. 
Final author version, cite as:

R. Payri, F. J. Salvador, P. Martí-Aldaraví, \& D. Vaquerizo, ECN Spray G external spray visualization and spray collapse description through penetration and morphology analysis, Applied Thermal

Engineering, vol. 112, pp. 304-316, 2017. doi:10.1016/j.applthermaleng.2016.10.023

As it was done in the density variations section 4.2, Fig 12 is introduced here. The figure compares the effect of gas temperature on spray angle at the same conditions than those in Fig 10. Unlike the gas density variations case, the usual effect of chamber gas temperature on spray angle goes in the same direction than the effect of temperature in spray collapse. It is expected that increasing gas temperature will decrease the liquid spray angle, as the evaporation of the liquid fuel is increased with higher temperatures. This is the effect that can be seen in the upper graph of Fig 12. However, the lower graph shows that when the density is higher (and consequently the collapsing of the injected spray is greater), the decay of spray angle occurs much more rapidly. This can be quantified by averaging the slope of the Spray Angle in a time range where the decay is approximately constant (in this case 900 - $1000 \mu \mathrm{s}$ ASOI). The average slope in the low density condition for the four temperatures is $-0.025 \mathrm{deg} / \mu \mathrm{s}$, whereas in the high density conditions is approximately $0.07 \mathrm{deg} / \mu \mathrm{s}$ (not including the lowest temperature for being non-evaporative).
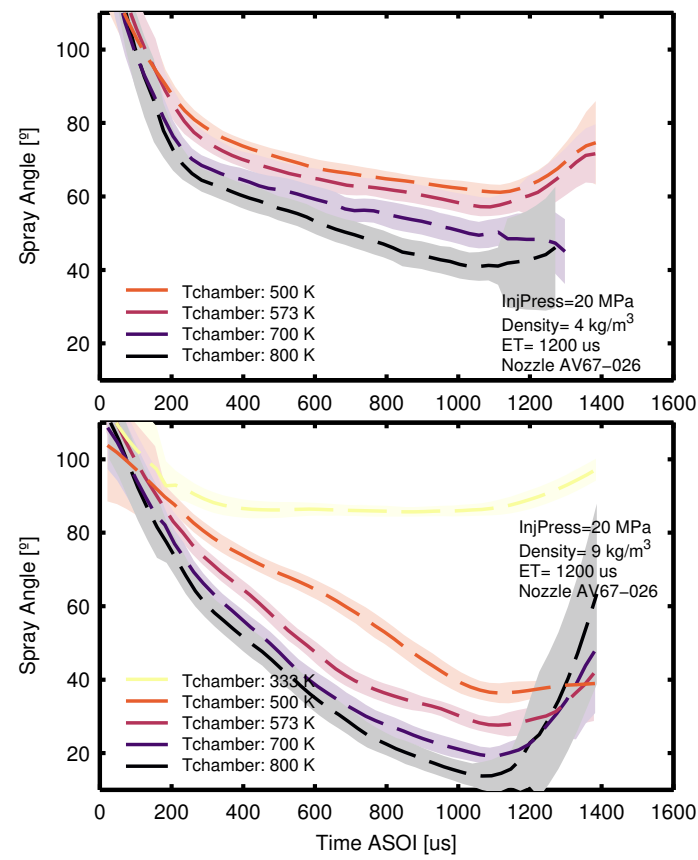

Figure 12: Temperature variations for $3 \mathrm{~kg} / \mathrm{m}^{3}$ density (top) and $9 \mathrm{~kg} / \mathrm{m}^{3}$ (bottom) and $20 \mathrm{MPa}$ injection pressure for liquid spray angle. 
Final author version, cite as:

R. Payri, F. J. Salvador, P. Martí-Aldaraví, \& D. Vaquerizo, ECN Spray G external spray visualization and spray collapse description through penetration and morphology analysis, Applied Thermal

Engineering, vol. 112, pp. 304-316, 2017. doi:10.1016/j.applthermaleng.2016.10.023

\subsection{Effect of injection pressure variation}

Another important parameter worth studying is the injection pressure given the variability that the parameter is subject to during the normal operation of an engine. Two injection pressure levels (10 MPa and $20 \mathrm{MPa}$ ) have been studied for all the gas density and temperature conditions tested. Fig 13 shows two graphs at the same level of temperature $(700 \mathrm{~K})$ and with a lower density at the top $\left(3 \mathrm{~kg} / \mathrm{m}^{3}\right)$ and a higher density at the bottom $(9$ $\mathrm{kg} / \mathrm{m}^{3}$ ) with liquid and vapor penetration lines at the two injection pressures specified.
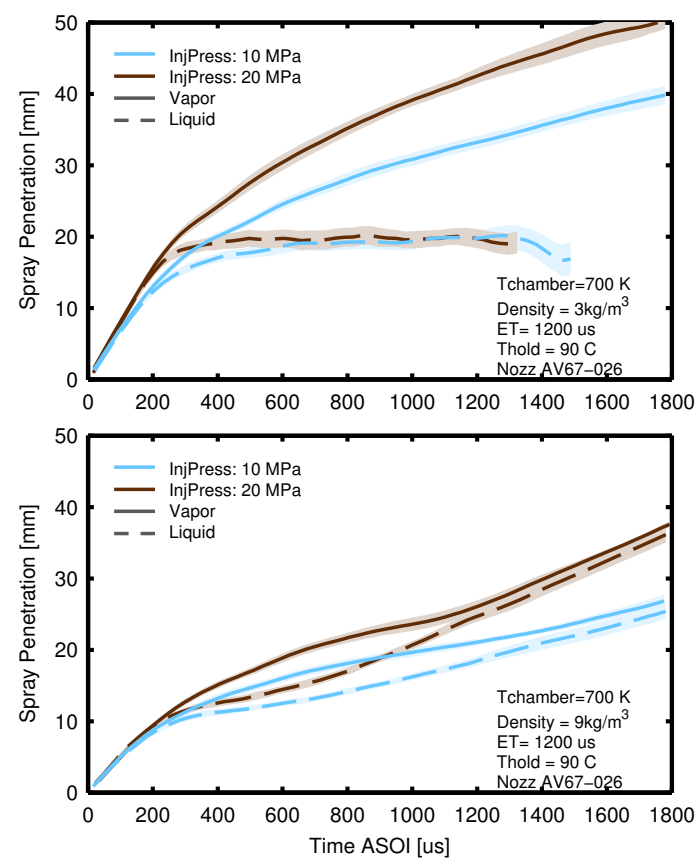

Figure 13: Injection pressure variations between a lower (top) and higher (bottom) level of chamber density at $700 \mathrm{~K}$ of chamber temperature for liquid and vapor penetration.

It can be noted how in the low density case, the injection pressure has the expected effect, greatly affecting vapor penetration but with no effects on the Liquid Length, which is in agreement with Diesel sprays literature $[27,32,33]$. However, when the density in the chamber increases to values previously shown in this work to produce spray collapse, stabilized Liquid Length is not reached, and an effect of injection pressure on liquid penetration is observed, being the effect very similar to that on the vapor penetration. 
Final author version, cite as:

R. Payri, F. J. Salvador, P. Martí-Aldaraví, \& D. Vaquerizo, ECN Spray G external spray visualization and spray collapse description through penetration and morphology analysis, Applied Thermal

Engineering, vol. 112, pp. 304-316, 2017. doi:10.1016/j.applthermaleng.2016.10.023

It can be hypothesized from the graph, that once the spray has begun to collapse, given the hindered evaporation of the fuel, the liquid phase starts to "follow" or behave like the vapor phase of the spray in terms of axial penetration. This effect is shown by the contour comparisons presented in Fig 14 where the contours detected with the image processing algorithms for vapor and liquid phases are plotted without the raw images. This type of visualization allows direct comparison of liquid and vapor penetration over the same graphs. It can be noted in the figure, that in the right-hand side column, where the density condition is significantly higher $\left(9 \mathrm{~kg} / \mathrm{m}^{3}\right.$ versus $3 \mathrm{~kg} / \mathrm{m}^{3}$ ), the liquid penetration grows following the vapor penetration very closely. Vapor penetration is encountering a higher density and therefore penetrating significantly less than on the left-hand side. This creates the particular shape of vapor contour clearly depicted in the bottom right of Fig 14 and also seen in Fig 11. The first part of the contour has a conical shape, and then spreads suddenly to an oval shape. Because of this fact, and as it was stated in section 3.2, no angle determination has been performed on the vapor contours gathered in the experiments, given that a robust definition that could represent the phenomena occurring at low and high density conditions, was not found. 
Final author version, cite as:

R. Payri, F. J. Salvador, P. Martí-Aldaraví, \& D. Vaquerizo, ECN Spray G external spray visualization and spray collapse description through penetration and morphology analysis, Applied Thermal Engineering, vol. 112, pp. 304-316, 2017. doi:10.1016/j.applthermaleng.2016.10.023
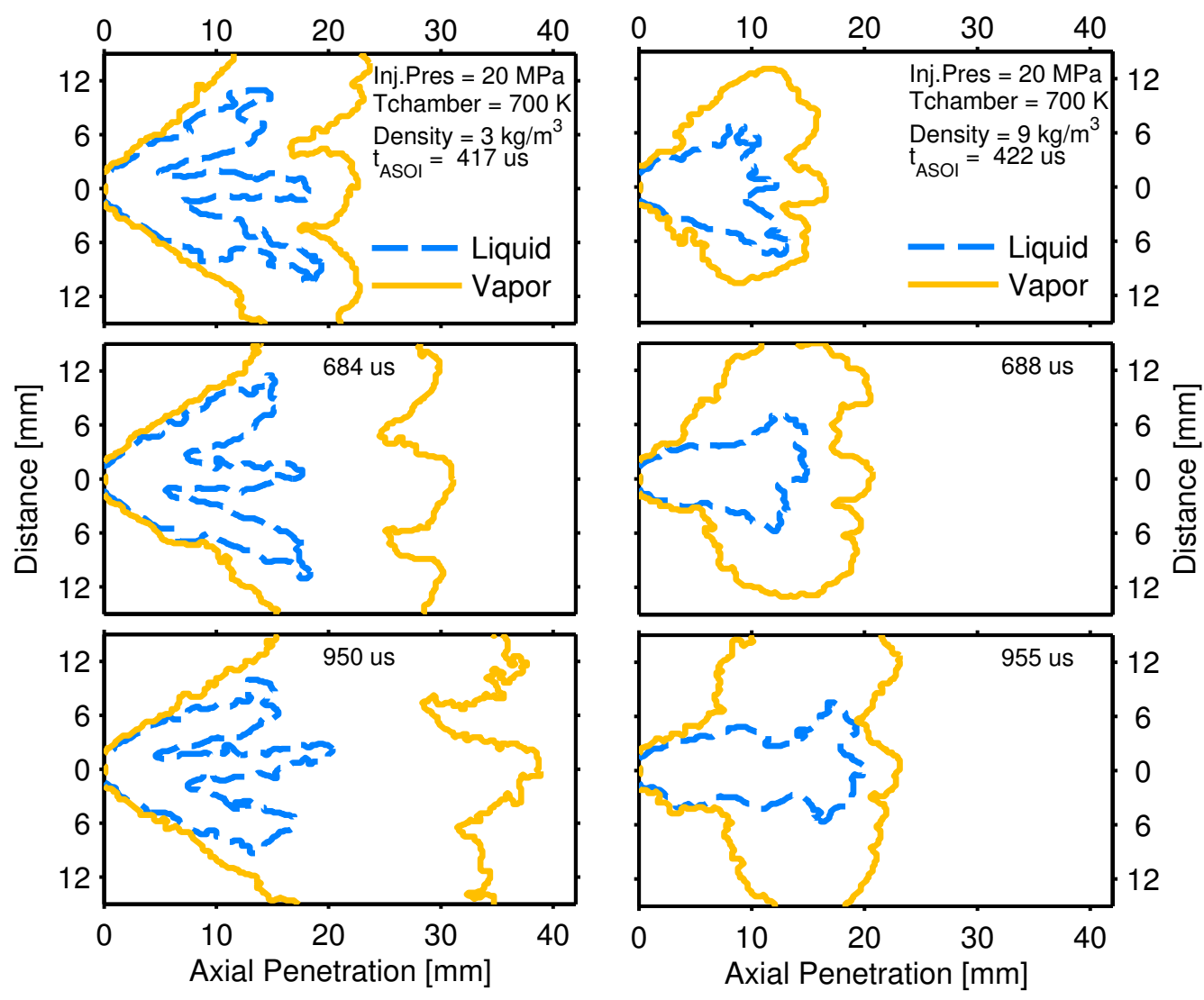

Figure 14: Liquid and vapor spray contours comparison between a lower (left) and a higher (right) density level at $700 \mathrm{~K}$ of chamber temperature and $20 \mathrm{MPa}$ injection pressure.

\subsection{Density and temperature variations}

The current section provides with a general overview of chamber temperature and density effects on spray collapse. Given the relationship shown between density and temperature and the angle decrease (Figs 8 and 12), one possibility to describe the spray collapse phenomena with a single scalar value is to take the minimum of the spray angle in a certain time window of the injection (900 to $1300 \mu \mathrm{s}$ ASOI). It should be noted that this analysis is often performed in other studies by averaging an stabilized zone of spray penetration or spray angle $[32,34]$. In this case however, since parameters like spray penetration and spray angle do not reach stabilization except for a few of the conditions tested, the minimum of the spray angle in the region near the end of injection was chosen. Fig 15 shows the minimum angle cal- 
Final author version, cite as:

R. Payri, F. J. Salvador, P. Martí-Aldaraví, \& D. Vaquerizo, ECN Spray G external spray visualization and spray collapse description through penetration and morphology analysis, Applied Thermal

Engineering, vol. 112, pp. 304-316, 2017. doi:10.1016/j.applthermaleng.2016.10.023

culated as previously stated for all of the conditions at $20 \mathrm{MPa}$ versus the chamber density (top graph) and versus temperature (bottom graph). Both graphs provide the same information visualized in a different way. In the top graph, it can be noted that the minimum of the spray angle is decreasing with increasing temperature (color saturation is ordered) which is expected given the higher evaporation rate at higher temperature. It can also be noted that for temperatures higher than $500 \mathrm{~K}$, the minimum spray angle decreases with increasing density, whereas for the two lower temperatures, the trend is the opposite (shown in 4.2 by Figs 8 and 9).

The aforementioned inverse relation between the minimum spray angle and the density escalate when density is increased. This result makes sense in view of previously presented results which reflected that the spray collapse intensifies the higher the chamber temperature and density become. Bottom graph of Fig 15 is very similar to the top graph, it can be clearly seen how the temperature almost has no effect on the spray angle when the density is $3 \mathrm{~kg} / \mathrm{m}^{3}$ or less, but when the density is higher than $4 \mathrm{~kg} / \mathrm{m}^{3}$, the spray angle decreases very rapidly with temperature.

Both graphs appearing in Fig 15 show the difficulty in developing empirical correlations for the parameter chosen to represent spray collapse given the change in trends and non-progressive behavior for some of the conditions. This underlines the importance of new research focusing on the understanding of the behavior of GDi sprays, due to the relation between the delivery and development of the fuel with evaporation and mixing (which directly affect the maps of fuel concentration) and the possibility of wall wetting; all with great influence in the combustion process and the generation of pollutants.

\section{Summary and conclusions}

Present work has shown results from DBI and Schlieren imaging techniques with the ECN Spray G hardware tested in a High Pressure and High Temperature constant pressure vessel. The extensive experimental campaign has allowed to gather data for conditions that have resulted useful to provide parametric variations to describe interesting phenomena taking place in this gasoline injector. Density, temperature and injection pressure variations have been shown through vapor and liquid penetration, liquid spray angle, images and detected contours in order to explain the general behavior of the spray, and to focus on the collapse of the spray from which little informa- 
Final author version, cite as:

R. Payri, F. J. Salvador, P. Martí-Aldaraví, \& D. Vaquerizo, ECN Spray G external spray visualization and spray collapse description through penetration and morphology analysis, Applied Thermal

Engineering, vol. 112, pp. 304-316, 2017. doi:10.1016/j.applthermaleng.2016.10.023
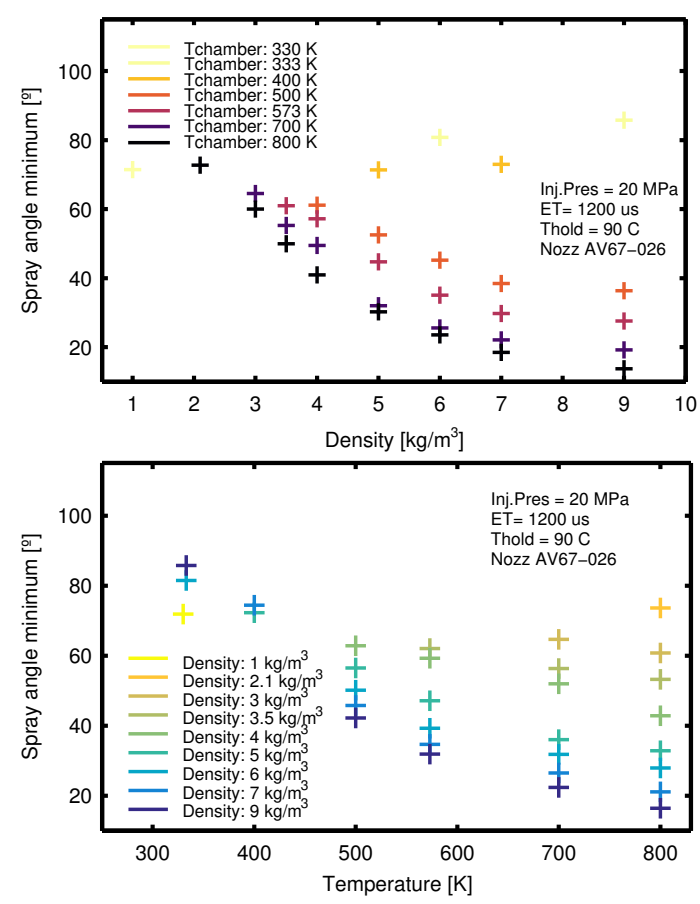

Figure 15: Minimum liquid spray angle calculated in the range of 900 to $1300 \mu s$ at 20 MPa injection pressure versus density (top) and temperature (bottom). The minimum spray angle has been chosen as a qualitative parameter to represent the degree of spray collapse.

tion is currently available. Spray collapse has been shown to have important consequences in the development of the fuel inside the chamber by causing a change in the expected behavior of liquid and vapor penetration, spray angle and morphology. The changes affect rate of evaporation and as a consequence, are likely to also affect mixing between fuel and air which is directly related to combustion and engine operation. The relations between spray penetration and spray angle with density and temperature were presented, and it was stated that spray collapse requires both parameters to be moderate or high to develop. It was shown that injection pressure does not directly affect spray collapse and that it has a similar effect on vapor penetration than in Diesel sprays. Furthermore, it was also stated that injection pressure does not change Liquid Length when the conditions allow to reach it, but when spray collapse prevents the stabilization of the liquid penetration, injection pressure has a similar effect on liquid penetration than on vapor 
Final author version, cite as:

R. Payri, F. J. Salvador, P. Martí-Aldaraví, \& D. Vaquerizo, ECN Spray G external spray visualization and spray collapse description through penetration and morphology analysis, Applied Thermal

Engineering, vol. 112, pp. 304-316, 2017. doi:10.1016/j.applthermaleng.2016.10.023

penetration. Lastly, the minimum of the spray angle in a time range close to the end of the injection was chosen to represent the degree of spray collapse and two graphs were presented with the information obtained. The graphs permitted variations of both temperature and density to be carried out at the same time and were useful to ratify and summarize the points made throughout the document about the general behavior of spray collapse with regards of chamber density and temperature. It was outlined in this last part of the results section the non-progressive behavior of spray collapse for some of the conditions, which led to the conclusions that more GDi spray research is necessary to understand the phenomena described, specially taking into account the effects it may have on evaporation, fuel mixing and wall wetting, all being of capital importance for combustion and engine operation.

\section{Acknowledgments}

This work was sponsored by "Ministerio de Economía y Competitividad" in the frame of the project "Estudio de la interacción chorro-pared en condiciones realistas de motor (SPRAY WALL)" reference TRA2015-67679c2-1-R.

Daniel Vaquerizo is partially supported through contract FPI-S2-20151069 of "Programa de Apoyo para la Investigación y Desarrollo (PAID)" of Universitat Politècnica de València. 
Final author version, cite as:

R. Payri, F. J. Salvador, P. Martí-Aldaraví, \& D. Vaquerizo, ECN Spray G external spray visualization and spray collapse description through penetration and morphology analysis, Applied Thermal

Engineering, vol. 112, pp. 304-316, 2017. doi:10.1016/j.applthermaleng.2016.10.023

\section{References}

[1] H. Zhao, Advanced direct injection combustion engine technologies and development, Woodhead Publishing Limited, Cambridge, ISBN 9788578110796, 2010.

[2] J. M. Luján, H. Climent, R. Novella, M. E. Rivas-Perea, Influence of a low pressure EGR loop on a gasoline turbocharged direct injection engine, Applied Thermal Engineering 89 (2015) 432-443, ISSN 13594311, doi:10.1016/j.applthermaleng.2015.06.039.

[3] J. Jeon, J. T. Lee, S. I. Kwon, S. Park, Combustion performance, flame, and soot characteristics of gasoline-diesel pre-blended fuel in an optical compression-ignition engine, Energy Conversion and Management $116 \quad(x) \quad$ (2016) 174183, ISSN 01968904, doi:10.1016/j.enconman.2016.03.003, URL http://dx.doi.org/10.1016/j.enconman.2016.03.003.

[4] J. Song, S. Park, Effect of injection strategy on the spray development process in a single-cylinder optical GDi engine., Atomization and Sprays 25 (9) (2015) 819-836, ISSN 1044-5110, doi: 10.1615/AtomizSpr.2015012018.

[5] Z. Zheng, C. Liu, X. Tian, X. Zhang, Numerical study of the effect of piston top contour on GDI engine performance under catalyst heating mode, Fuel 157 (2015) 64-72, ISSN 00162361, doi:10.1016/j.fuel.2015.04.054, URL http://dx.doi.org/10.1016/j.fuel.2015.04.054.

[6] Z. H. Li, B. Q. He, H. Zhao, Application of a hybrid breakup model for the spray simulation of a multi-hole injector used for a DISI gasoline engine, Applied Thermal Engineering 65 (1-2) (2014) 282292, ISSN 13594311, doi:10.1016/j.applthermaleng.2013.12.063, URL http://dx.doi.org/10.1016/j.applthermaleng.2013.12.063.

[7] P. Strek, D. Duke, A. Swantek, A. Kastengren, C. F. Powell, D. P. Schmidt, X-Ray Radiography and CFD Studies of the Spray G Injector, in: SAE Technical Paper 2016-01-0858, doi:10.4271/2016-01-0858, URL http://papers.sae.org/2016-01-0858/, 2016. 
Final author version, cite as:

R. Payri, F. J. Salvador, P. Martí-Aldaraví, \& D. Vaquerizo, ECN Spray G external spray visualization and spray collapse description through penetration and morphology analysis, Applied Thermal

Engineering, vol. 112, pp. 304-316, 2017. doi:10.1016/j.applthermaleng.2016.10.023

[8] Engine Combustion Network, ECN Spray G, URL http://www.sandia.gov/ecn/G/targetCondition/sprayG.php, 2016.

[9] R. Payri, J. Gimeno, P. Martí-Aldaraví, D. Vaquerizo, Internal flow characterization on an ECN GDi injector, Atomization and Sprays 26 (9) (2015) 889-919, doi:10.1615/AtomizSpr.2015013930.

[10] M. Moulai, R. Grover, S. Parrish, D. Schmidt, Internal and Near-Nozzle Flow in a Multi-Hole Gasoline Injector Under Flashing and Non-Flashing Conditions, SAE Technical Paper 2015-01-0944 (2015-01-0944), doi:10.4271/2015-01-0944, URL http://papers.sae.org/2015-01-0944/.

[11] S. Moon, K. Komada, K. Sato, H. Yokohata, Y. Wada, N. Yasuda, Ultrafast X-ray study of multi-hole GDI injector sprays: Effects of nozzle hole length and number on initial spray formation, Experimental Thermal and Fluid Science 68 (2015) 68-81, ISSN 08941777, doi:10.1016/j.expthermflusci.2015.03.027, URL http://dx.doi.org/10.1016/j.expthermflusci.2015.03.027 http://linkinghub.elsevier.com/retrieve/pii/S0894177715000965.

[12] Q. Cheng, M. Xu, Z. Zhang, N. Xie, Investigation on the spray characteristics of standard gasoline, n-pentane, iso-octane and ethnaol with a novel heated tip SIDI injector, Applied Thermal Engineering 110 (2017) 539-552, ISSN 13594311, doi:10.1016/j.applthermaleng.2016.07.201, URL http://dx.doi.org/10.1016/j.applthermaleng.2016.07.201.

[13] K. Saha, S. Som, M. Battistoni, Y. Li, E. Pomraning, P. K. Senecal, Numerical Investigation of Two-Phase Flow Evolution of Inand Near-Nozzle Regions of a Gasoline Direct Injection Engine During Needle Transients, SAE International Journal of Engines 9 (2) (2016) 2016-01-0870, ISSN 1946-3944, doi:10.4271/2016-01-0870, URL http://papers.sae.org/2016-01-0870/.

[14] A. Montanaro, L. Allocca, Flash Boiling Evidences of a Multi-Hole GDI Spray under Engine Conditions by Mie-Scattering Measurements, SAE Technical Paper 2015-01-1945 . 
Final author version, cite as:

R. Payri, F. J. Salvador, P. Martí-Aldaraví, \& D. Vaquerizo, ECN Spray G external spray visualization and spray collapse description through penetration and morphology analysis, Applied Thermal

Engineering, vol. 112, pp. 304-316, 2017. doi:10.1016/j.applthermaleng.2016.10.023

[15] J. Manin, Y. Jung, S. A. Skeen, L. M. Pickett, S. E. Parrish, L. E. Markle, Experimental Characterization of DI Gasoline Injection Processes, SAE Technical Paper 2015-01-1894 doi:10.4271/2015-01-1894.

[16] J. S. Lacey, F. Pourzakadeh, M. Brear, P. Petersen, C. Lakey, S. Ryan, B. Butcher, Optical Characterization of Propane at Representative Spark Ignition, Gasoline Direct Injection Conditions, SAE International Journal of Engines (2016-01-0842) (2016) 21-23, doi:10.4271/2016-010842.Copyright.

[17] W. Zeng, M. Xu, M. Zhang, Y. Zhang, D. J. Cleary, Macroscopic characteristics for direct-injection multi-hole sprays using dimensionless analysis, Experimental Thermal and Fluid Science 40 (2012) 81-92, ISSN 08941777, doi:10.1016/j.expthermflusci.2012.02.003, URL http://dx.doi.org/10.1016/j.expthermflusci.2012.02.003.

[18] R. Payri, J. Gimeno, J. P. Viera, A. H. Plazas, Needle lift profile influence on the vapor phase penetration for a prototype diesel direct acting piezoelectric injector, Fuel 113 (2013) 257-265, ISSN 00162361, doi:10.1016/j.fuel.2013.05.057, URL http://www.sciencedirect.com/science/article/pii/S0016236113004699 http://dx.doi.org/10.1016/j.fuel.2013.05.057.

[19] M. Bardi, R. Payri, L.-M. Malbec, G. Bruneaux, L. M. Pickett, J. Manin, T. Bazyn, C. L. Genzale, Engine Combustion Network: Comparison of Spray Development, Vaporization, and Combustion in Different Combustion Vessels, Atomization and Sprays 22 (10) (2012) 807-842, ISSN 1044-5110, doi:10.1615/AtomizSpr.2013005837.

[20] R. Payri, J. P. Viera, Y. Pei, S. Som, Experimental and numerical study of lift-off length and ignition delay of a two-component diesel surrogate, Fuel $158 \quad$ (2015) 957967, ISSN 00162361, doi:10.1016/j.fuel.2014.11.072, URL http://linkinghub.elsevier.com/retrieve/pii/S0016236114011764.

[21] J. Benajes, R. Payri, M. Bardi, P. Martí-aldaraví, Experimental characterization of diesel ignition and lift-off length using a single-hole ECN injector, Applied Thermal Engineering 58 (1-2) (2013) 554563, ISSN 13594311, doi:10.1016/j.applthermaleng.2013.04.044, URL 
Final author version, cite as:

R. Payri, F. J. Salvador, P. Martí-Aldaraví, \& D. Vaquerizo, ECN Spray G external spray visualization and spray collapse description through penetration and morphology analysis, Applied Thermal

Engineering, vol. 112, pp. 304-316, 2017. doi:10.1016/j.applthermaleng.2016.10.023

http://www.sciencedirect.com/science/article/pii/S1359431113003153 http://dx.doi.org/10.1016/j.applthermaleng.2013.04.044.

[22] M. Blessinger, J. Manin, S. A. Skeen, M. Meijer, S. E. Parrish, L. M. Pickett, Quantitative mixing measurements and stochastic variability of a vaporizing gasoline direct-injection spray, International Journal of Engine Research 16 (2) (2015) 238-252, ISSN 1468-0874, doi:Doi 10.1177/1468087414531971, URL //wos <Go to ISI $>$ : //WOS : 000349225300009 .

[23] J. Manin, M. Bardi, L. M. Pickett, Evaluation of the liquid length via diffused back-illumination imaging in vaporizing diesel sprays, in: Comodia, Fukuoka, 2012.

[24] M. Meijer, L.-M. M. Malbec, G. Bruneaux, L. M. T. Somers, Engine Combustion Network:Spray A'Basic Measurements and Advanced Diagnostics, in: ICLASS 2012, 12th Triennial International Conference on Liquid Atomization and Spray Systems, 2-6, 2012.

[25] V. Macian, R. Payri, A. Garcia, M. Bardi, Experimental evaluation of the best approach for diesel spray images segmentation, Experimental Techniques 36 (6) (2012) 26-34, ISSN 07328818, doi:10.1111/j.1747-1567.2011.00730.x, URL http://doi.wiley.com/10.1111/j.1747-1567.2011.00730.x.

[26] R. Payri, J. Gimeno, M. Bardi, A. Plazas, Effect of Injection Rate Shaping Over Diesel Spray Development in Non Reacting Evaporative Conditions, in: ASME 2012 Internal Combustion Engine Division Spring Technical Conference, ASME, Torino, Italy, ISBN 978-0-7918-4466-3, ISSN 15296598, 347, doi:10.1115/ICES2012-81206, 2012.

[27] D. L. Siebers, Scaling liquid-phase fuel penetration in diesel sprays based on mixing-limited vaporization, SAE Technical Paper 1999-01-0528 ISSN 0148-7191, doi:10.4271/1999-01-0528, URL http://subscriptions. sae. org/content/1999-01-0528/.

[28] R. Payri, J. Gimeno, J. P. Viera, A. H. Plazas, Schlieren visualization of transient vapor penetration and spreading angle of a prototype diesel direct-acting piezoelectric injector, in: ICLASS 2012, 1-8, 2012. 
Final author version, cite as:

R. Payri, F. J. Salvador, P. Martí-Aldaraví, \& D. Vaquerizo, ECN Spray G external spray visualization and spray collapse description through penetration and morphology analysis, Applied Thermal

Engineering, vol. 112, pp. 304-316, 2017. doi:10.1016/j.applthermaleng.2016.10.023

[29] W. Zeng, M. Xu, G. Zhang, Y. Zhang, D. J. Cleary, Atomization and vaporization for flash-boiling multi-hole sprays with alcohol fuels, Fuel 95 (2012) 287-297, ISSN 00162361, doi:10.1016/j.fuel.2011.08.048, URL http://www. sciencedirect. com/science/article/pii/S0016236111005229.

[30] S. E. Parrish, R. J. Zink, Development and Application of Imaging System To Evaluate Liquid and Vapor Envelopes of Multi-Hole Gasoline Fuel Injector Sprays Under Engine-Like Conditions, Atomization and Sprays 22 (8) (2012) 647-661, ISSN 1044-5110, doi: 10.1615/AtomizSpr.2012006215.

[31] M. Blessinger, M. Meijer, L. Pickett, J. Manin, S. Skeen, Liquid/Vapor penetration and plume-plume interaction of vaporizing iso-octane and ethanol SIDI sprays, in: ILASS Americas, 25th Annual Conference on Liquid Atomization and Spray Systems, Pittisburgh PA, -, 2013.

[32] R. Payri, J. Gimeno, G. Bracho, D. Vaquerizo, Study of liquid and vapor phase behavior on Diesel sprays for heavy duty engine nozzles, Applied Thermal Engineering 107 (2016) 365-378, ISSN 13594311, doi:10.1016/j.applthermaleng.2016.06.159, URL http://linkinghub.elsevier.com/retrieve/pii/S1359431116310730.

[33] J. D. Naber, D. L. Siebers, Effects of Gas Density and Vaporization on Penetration and Dispersion of Diesel Sprays, in: SAE Paper 960034, vol. 105, Society of Automotive Engineers, Inc., Warrendale, Pennsylvania, USA, ISBN 0096-736X, 82--111, doi:10.4271/960034, URL http://papers.sae.org/960034/, 1996.

[34] J. M. Desantes, R. Payri, F. J. Salvador, A. Gil, Development and validation of a theoretical model for diesel spray penetration, Fuel 85 (7-8) (2006) 910-917, URL http://www.sciencedirect.com/science/article/pii/S0016236105004084. 